\title{
The Impact of Fiscal Subsidies on the Sustainability of China's Rural Pension Program
}

\author{
Benxi Lin ${ }^{1, *}$ and Yu Yvette Zhang ${ }^{2}$ \\ 1 School of Economics, Fujian Agriculture and Forestry University, Fuzhou 350002, China \\ 2 Department of Agricultural Economics, Texas A\&M University, College Station, TX 77843, USA; \\ yzhang@tamu.edu \\ * Correspondence: bxlin@fafu.edu.cn
}

Received: 13 November 2019; Accepted: 24 December 2019; Published: 25 December 2019

\begin{abstract}
This paper studies the impact of fiscal subsidies on the sustainability of China's rural pension system. We first provide an overview of China's rural pension system, and explain the formulas used to calculate the pension payments. We then examine how fiscal subsidies, in the forms of basic pensions, incentive pensions, and matching subsidies, affect participation rates and individual contributions. Our study shows that the rural residents' participation rates can be improved significantly by increasing basic pensions or by providing incentive pensions, but not by providing matching subsidies. However, none of these fiscal subsidies have significant effects on the amount of individual contributions. Overall, our results imply that the incentive pension is an effective mechanism in encouraging rural residents to participate in pension programs, but the current level of matching subsidies is not sufficient to improve participation or increase contributions. Our study suggests the needs to increase the fiscal subsides used in China's rural pension system, and can provide useful implications in designing the effective pension system for rural residents.
\end{abstract}

Keywords: Chinese Pension System; New Rural Pension Scheme (NPRS); Fiscal Subsidies; Incentive Pension; Matching Subsidy

\section{Introduction}

China's population is aging faster than that of almost any other country in the world. In 2030, China will become the worlds' most aged society [1], and the proportion of the elderly population aged 65 or older in China will double from 10\% to $20 \%$ in 20 years (2017-2037) [2]. The elderly proportion of the rural population in China is higher than that of the urban population, with the rural areas also aging faster than the urban areas [3]. Moreover, the rural elderly have higher rates of poverty than the urban elderly [4]. Historically, the Chinese rural elderly have relied heavily on their adult children as their main source of financial support. This traditional informal system of old-age provision has been weakening with the increased rural-to-urban migration flows as well as the higher life expectancy and lower fertility rate since the economic reforms in the 1980s [5-7]. China needs a sustainable pension system with a broad coverage and adequate benefits to provide a social safety net addressing the needs of the rural aging population. In this paper, we study the effects of fiscal subsidies on the sustainability of the rural pension system. In particular, we investigate whether the participation rates and contribution amounts can be improved by introducing an extra pension payment (Incentive Pension) for people who contribute to the program for a long enough period of time.

The nationwide rural pension system in China was not established until 2009, when China launched the New Rural Pension Scheme (NRPS) aiming to provide income support for rural elderly. The NRPS was preceded by several county-level pilot schemes starting in 1986 when the Chinese State Council issued its 7th Five Year Plan, which noted that "efforts should be made to study 
how to establish a rural pension system, launch and gradually expand pilot schemes in line with economic development" [8]. The NRPS has rapidly expanded since its implementation in 2009 and covered all regions of rural China in 2012. Meanwhile, the Urban Resident Social Pension (URSP) program was implemented in 2011 to cover the urban nonwage residents who were not covered by the employee-based pension programs. Following Doc. 8 published by the State Council of China in 2014, the NRPS and URSP were merged into one unified pension system, the Urban and Rural Residents Basic Pension System (URBP), for all nonwage rural and urban residents. By the end of 2018, 532.91 million rural and urban residents had enrolled in URBP with a coverage rate higher than $85 \%$, making URBP the pension program with the largest number of participants in the world [9]. Despite the rapid development of this program, many studies have found that rural residents, especially younger residents, do not have sufficient incentives to participate, and most people who do participate choose the lowest level of contribution [10].

The data used in our study are from an NRPS subsidy program in Fujian Province of China. Fujian Province, located on the southeast coast of China, is one of the richest provinces in China but with significant intraprovincial disparities largely due to an income gap between rural and urban areas [11,12]. According to China National Bureau of Statistics, Fujian's GDP per capita in 2018 ranks sixth in the nation, although it is actually the third highest province after Jiangsu and Zhejiang if the three municipalities of Beijing, Shanghai, and Tianjin are excluded. Fujian province was one of the earliest provinces to introduce the Incentive Pension in the NRPS program, which will be explained in detail in the next section. Our data are from 2011 to 2013, when the NRPS and URSP were still operating in parallel before they merged into the URBP in 2014. The URBP adopted the basic schemes, approaches, and pension benefit formulas from the NRPS, and currently serves as the main rural pension program in China. Therefore, our study with this unique data set of NRPS can provide very useful implications in designing an effective pension system for rural residents.

The rest of this paper is organized as follows. Section 2 explains the calculation of the pension payment in Chinese pension system. Section 3 describes the data used in our study and presents the data analysis. Section 4 discusses the results and provides policy implications.

\section{Pension Formulas}

In this section we will explain the NRPS pension formulas, which still apply to the current URBP program. According to Doc. 32 published by the State Council of China in 2009, all rural residents aged 16 or above (excluding students) who are not enrolled in the urban pension programs can participate in the NRPS voluntarily. The NRPS allows participants to receive a pension starting from age 60 after providing 15 years of contributions. Participants aged 45 or over when enrolling in NRPS will be required to make a lump-sum payment to cover the shortfall years. The pension consists of two components: a basic pension component and an individual account with individual contribution and matching subsidy.

The basic pension varies across different regions/counties according to local government policies with a minimum of 55 CNY per month set by the central government in 2009 (http://www.gov.cn/zwgk/2009-09/04/content_1409216.htm), and later raised to 88 CNY per month in 2018 (http://www.gov.cn/xinwen/2018-05/13/content_5290630.htm). Matching and management of the individual accounts are determined by local governments with the minimum contribution of $100 \mathrm{CNY}$ required by the central government. The matching subsidy starts at $30 \mathrm{CNY}$ for the minimum contribution of $100 \mathrm{CNY}$ with an increment of $5 \mathrm{CNY}$ for every additional $100 \mathrm{CNY}$ of contributions, and is capped at a maximum level (maximum matching subsidy) set by local governments. This type of matching defined contribution (MDC) approach has been shown to increase pension coverage and saving rates in many countries [13]. However, its effect in China is either insignificant or unclear as 
most contributors have weak incentives to contribute above the minimum level $[4,14]$. Under this scheme, the pension (monthly) formula is hence as follows,

$$
\text { Pension_Payment }=\text { Basic_Pension }+\left[\sum_{t=1}^{T}\left(\text { Contribution }_{t}+\text { Match }_{t}\right) \times(1+r)^{T-t}\right] / 139,
$$

where the second part represents the amounts accumulated in the individual accounts of the beneficiary including accrued interests, with $r$ being the One-Year Term Deposits interest rate and $T$ being the total years of contribution. Note that the individual account is calculated in a yearly base but the beneficiary will receive the pension monthly. Therefore, in formula (1), Pension Payment and Basic Pension are monthly values, while Contribution and Match (matching subsidy) are annual values. The actuarial factor 139 is the expected months of life after retirement at age 60 based on a life expectancy of 71.5 years in 2009, and this actuarial factor is still used in the current URBP program.

Fujian Province has taken several measures to ensure sustained participation of rural residents, including providing an incentive pension and increasing the matching subsidy. It was one of the earliest provinces to include an incentive pension in the program in starting 2011, aiming to encourage the participation of residents under the age of 45 in particular. Under this scheme, if a person has contributed to the program for more than 15 years, he or she will receive an extra pension payment (an Incentive Pension) for each additional year of contribution beyond 15 years. The amount for the incentive pension is decided by local governments, and in many areas is around $1 \%$ of basic pension but the amount may vary slightly in different counties. The pension formula then takes the form,

$$
\text { Pension_Payment }=\left\{\begin{array}{c}
\text { Basic_Pension }+\left[\sum_{t=1}^{T}\left(\text { Contribution }_{t}+\text { Match }_{t}\right) \times(1+r)^{T-t}\right] / 139, \text { if } T<15, \\
\text { Basic_Pension + Incentive_Pension } \times(T-15)+\left[\sum_{t=1}^{T}\left(\text { Contribution }_{t}+\text { Match }_{t}\right) \times(1+r)^{T-t}\right] / 139, \text { if } T \geq 15 .
\end{array}\right.
$$

\section{Data}

This paper uses regional statistical data from the NRPS program during 2011-2013 from 64 counties of Fujian Province provided by Fujian Urban and Rural Residents Social Insurance Administration Center and data from Fujian Statistical Year Books (2011-2013). The incentive pension scheme was implemented in four out of these 64 counties in 2011, 27 counties in 2012, and 33 counties in 2013. We have obtained county-level information including the participation rates (for different age groups), basic pension, average contribution, whether the county implemented the incentive pension scheme, and other basic statistics for each county in each year. The descriptions of county-level summary statistics and variables used in our analysis are presented in Table 1.

Table 1. Definition of Variables and Descriptive Statistic.

\begin{tabular}{cccc}
\hline Variable & Definition & Mean & SD \\
\hline ParticipationRate & Percentage of eligible people enrolled & $83.10 \%$ & $13.70 \%$ \\
Contribution & Average individual contribution per year (CNY) & 130.42 & 31.96 \\
BasicP & Basic Pension per month (CNY) & 59.48 & 9.85 \\
IncentiveP & If implemented incentive pension (=1) & $33.33 \%$ & $47.18 \%$ \\
MaxMatch & Maximum matching subsidy per year (CNY) & 57.87 & 17.64 \\
Income & Annual per capita income (CNY) & 8954.49 & 1951.94 \\
MaleRatio & Proportion of male participants & $50.62 \%$ & $1.90 \%$ \\
\multicolumn{2}{c}{ Proportion of participants age $<30$ and $>16$} & $17.58 \%$ & $5.36 \%$ \\
\multicolumn{2}{c}{ Proportion of participants age $\geq 30$ and $<45$} & $40.54 \%$ & $3.34 \%$ \\
& Proportion of participants age $\geq 45$ & $41.88 \%$ & $6.38 \%$ \\
Urbanization & Proportion of urban population & $49.86 \%$ & $15.86 \%$ \\
\hline
\end{tabular}




\section{Analytical Methods and Results}

We first estimated the effect of fiscal subsides on the participation rates of the rural residents. In our data, we have participation rates for three age groups: people younger than 30 but older than 16 (Age1), older than 30 but younger than 45 (Age 2), and older than 45 (used as the base case for all age groups). Since the participation rate in our analysis takes values between 0 and 1 , we assume it follows a Beta distribution defined on the interval $[0,1]$ and perform a beta regression [15],

$$
\begin{aligned}
R_{\text {ait }}=\alpha_{0}+ & \alpha_{1} \text { IncentiveP }_{i t}+\alpha_{2} \text { BasicP }_{i t}+\alpha_{3} \text { MaxMatch }_{i t}+\alpha_{4} \text { Age }_{1 i t}+\alpha_{5} \text { Age }_{2 i t} \\
& +\alpha_{6} \text { Age }_{1 \text { it }} \times \text { IncentiveP }_{i t}+\alpha_{7} \text { Age }_{2} \times \text { IncentiveP }_{i t}+\alpha_{8} \text { MaleRatio }_{i t} \\
& +\alpha_{9} \text { Income }_{i t}+\alpha_{10} \text { Urbanization }_{i t}+\epsilon_{\text {ait }},
\end{aligned}
$$

where $R_{a i t}$ is the participation rate, the subscripts $a$ is the age group, $i$ is the county, $t$ is the year, and $A g e_{1}=1$ if the age group is between 16 and 30, and $A g e_{2}=1$ if the age group is between 30 and 45 , with the age group of older than 45 being the base group. The definitions of other variables in this regression are described in Table 1. We used the interaction terms of age groups $\left(A g e_{1}, A g e_{2}\right)$ and the incentive pension provision to investigate whether the incentive pension had different effects for different age groups. We also examined the effects of some basic regional information such as the gender ratio, average income per capita, and urbanization rate, which is defined as the proportion of urban population at the year-end. We also performed a logit transformation regression [16], which takes the form,

$$
\begin{aligned}
\log \left(\frac{R_{\text {ait }}}{1-R_{\text {ait }}}\right)=\alpha_{0} & +\alpha_{1} \text { IncentiveP }_{i t}+\alpha_{2} \text { Basic }_{i t}+\alpha_{3} \text { MaxMatch }_{i t}+\alpha_{4} \text { Age }_{1 \text { it }} \\
& +\alpha_{5} \text { Age }_{2 i t}+\alpha_{6} \text { Age }_{1_{i t}} \times \text { IncentiveP }_{i t}+\alpha_{7} \text { Age }_{2_{i t}} \times \text { IncentiveP }_{i t} \\
& +\alpha_{8} \text { MaleRatio }_{i t}+\alpha_{9} \text { Income }_{i t}+\alpha_{10} \text { Urbanization }_{i t}+\epsilon_{\text {ait }} .
\end{aligned}
$$

In addition, fractional logit regression and fraction probit regression were also performed. All four regressions yielded similar results as presented in Table 2 .

Our analysis shows that the participation rates significantly increases with the provision of incentive pension. The participation rates of young people (age $<30)$ are significantly lower than people older than 45 , and the effects of incentive pension on participations is smaller for young people than for people older than 45. People in counties with a higher per-capita income and urbanization level are more willing to participate in the pension programs. Not surprisingly, higher basic pension rates cause an increase in the participation rates. What is puzzling in the results is that the participation rates decrease with the maximum matching subsidy, possibly due to the endogeneity problem. In our future study, we hope to use county-level data to obtain adequate instrumental variables and address the endogeneity problem.

We then explored the effects of fiscal subsidies, especially matching subsidies, on individual contributions controlling for the county-specific effects. In our data, we had average individual contributions in each county, which was used as the dependent variable in the analysis. Since we did not have contribution amounts for each age group, we used the proportion of participants older than 45 (EldRate) instead of age group dummies in the analysis. The regression model takes the following form

$$
\begin{aligned}
& \text { Contribution }_{i t}=\alpha_{0}+\alpha_{1} \text { IncentiveP }_{i t}+\alpha_{2} \text { Basic }_{i t}+\alpha_{3} \text { MaxMatch }_{i t}+\alpha_{4} \text { EldRate }_{i t}+ \\
& \alpha_{5} \text { MaleRatio }_{i t}+\alpha_{6} \text { Income }_{i t}+\alpha_{7} \text { Urbanization }_{i t}+\epsilon_{i t},
\end{aligned}
$$

where the subscripts $i$ is the county and $t$ is the year. We first perform the Hausman test to differentiate between the fixed-effects model and the random-effects model, and the null hypothesis is rejected $(\mathrm{P}<0.000)$ implying the fixed-effects model is more preferred. While the fixed-effects model can answer the questions about the effects of fiscal subsidies when the policies change over time for the same county, the between-effects model can provide the matching subsidy effects when it differs between counties. The results of both fixed-effects and between-effect regressions are presented in Table 3. 
Table 2. The Effects of Incentive Pension on Participation Rates.

\begin{tabular}{|c|c|c|c|c|}
\hline & $\begin{array}{l}\text { Beta Regression } \\
\quad(n=576)\end{array}$ & $\begin{array}{l}\text { Logit Transformation } \\
\qquad(n=576)\end{array}$ & $\begin{array}{l}\text { Fractional Logit } \\
\qquad(n=576)\end{array}$ & $\begin{array}{l}\text { Fractional Probit } \\
\qquad(n=576)\end{array}$ \\
\hline Intercept & $\begin{array}{c}0.5912 \\
(0.7107) \\
\end{array}$ & $\begin{array}{c}0.1996 \\
(0.8081)\end{array}$ & $\begin{array}{c}0.5919 \\
(0.7784)\end{array}$ & $\begin{array}{c}0.4283 \\
(0.4245)\end{array}$ \\
\hline IncentiveP & $\begin{array}{l}0.2120 * \\
(0.1158)\end{array}$ & $\begin{array}{l}0.2357 * \\
(0.1241)\end{array}$ & $\begin{array}{c}0.3755^{* * *} \\
(0.1220)\end{array}$ & $\begin{array}{c}0.1971 * * * \\
(0.0648)\end{array}$ \\
\hline Age $_{1}$ & $\begin{array}{c}-0.3281^{* *} \\
(0.1267)\end{array}$ & $\begin{array}{c}-0.4918^{* * *} \\
(0.1492)\end{array}$ & $\begin{array}{l}-0.2806 * \\
(0.1455)\end{array}$ & $\begin{array}{c}-0.1697 * * \\
(0.0809)\end{array}$ \\
\hline $\mathrm{Age}_{2}$ & $\begin{array}{l}-0.0427 \\
(0.1008)\end{array}$ & $\begin{array}{l}-0.1060 \\
(0.1154)\end{array}$ & $\begin{array}{l}-0.0306 \\
(0.1284)\end{array}$ & $\begin{array}{l}-0.0232 \\
(0.0703)\end{array}$ \\
\hline Age $_{1}$ x IncentiveP & $\begin{array}{l}-0.2067 \\
(0.1529)\end{array}$ & $\begin{array}{l}-0.2806 \\
(0.1720)\end{array}$ & $\begin{array}{c}-0.3301 * * \\
(0.1587)\end{array}$ & $\begin{array}{c}-0.1695 * \\
(0.0862)\end{array}$ \\
\hline $\mathrm{Age}_{2} \mathrm{x}$ IncentiveP & $\begin{array}{l}-0.1248 \\
(0.1589) \\
\end{array}$ & $\begin{array}{l}-0.1868 \\
(0.1720) \\
\end{array}$ & $\begin{array}{l}-0.1765 \\
(0.1702)\end{array}$ & $\begin{array}{l}-0.0897 \\
(0.0914) \\
\end{array}$ \\
\hline BasicP & $\begin{array}{c}0.0135 * * * \\
(0.0040)\end{array}$ & $\begin{array}{c}0.0204^{* * *} \\
(0.0040)\end{array}$ & $\begin{array}{c}0.0184^{* * *} \\
(0.0042)\end{array}$ & $\begin{array}{c}0.0096^{* * *} \\
(0.0022)\end{array}$ \\
\hline MaxMatch & $\begin{array}{c}-0.0040 * \\
(0.0021)\end{array}$ & $\begin{array}{l}-0.0039 \\
(0.0024) \\
\end{array}$ & $\begin{array}{l}-0.0039 \\
(0.0040) \\
\end{array}$ & $\begin{array}{l}-0.0021 \\
(0.0021)\end{array}$ \\
\hline MaleRatio & $\begin{array}{l}-1.8550 \\
(1.3644) \\
\end{array}$ & $\begin{array}{l}-1.3407 \\
(1.5718) \\
\end{array}$ & $\begin{array}{c}-2.8154 * \\
(1.5291)\end{array}$ & $\begin{array}{c}-1.4488 * \\
(0.8419)\end{array}$ \\
\hline Income & $\begin{array}{c}0.0001^{* * *} \\
(0.0000)\end{array}$ & $\begin{array}{c}0.0001^{* * *} \\
(0.0000)\end{array}$ & $\begin{array}{c}0.0002 * * * \\
(0.0000)\end{array}$ & $\begin{array}{c}0.0001 * * * \\
(0.0000)\end{array}$ \\
\hline Urbanization & $\begin{array}{c}0.0066^{* * *} \\
(0.0022)\end{array}$ & $\begin{array}{c}0.0074 * * * \\
(0.0024)\end{array}$ & $\begin{array}{c}0.0064^{* * *} \\
(0.0025)\end{array}$ & $\begin{array}{c}0.0032 * * * \\
(0.0013)\end{array}$ \\
\hline $\begin{array}{l}\mathrm{AIC} \\
\mathrm{BIC}\end{array}$ & $\begin{array}{l}-1084.50 \\
-1032.23\end{array}$ & $\begin{array}{l}1380.25 \\
1428.16\end{array}$ & $\begin{array}{l}527.02 \\
574.94\end{array}$ & $\begin{array}{l}527.49 \\
575.41\end{array}$ \\
\hline
\end{tabular}

Notes: Standard errors are presented in parentheses; ${ }^{*}$ significant at $10 \% ;{ }^{* *}$ significant at $5 \%$; ${ }^{* * *}$ significant at $1 \%$.

Table 3. The effects of fiscal subsidies on individual contributions.

\begin{tabular}{|c|c|c|c|c|}
\hline & \multicolumn{2}{|c|}{$\begin{array}{l}\text { Fixed-Effects } \\
\quad(n=192)\end{array}$} & \multicolumn{2}{|c|}{$\begin{array}{l}\text { Between-Effects } \\
(n=192)\end{array}$} \\
\hline & Coef. & $p$ Value & Coef. & $p$ Value \\
\hline Intercept & $\begin{array}{c}492.8737^{* * *} \\
(151.175)\end{array}$ & 0.001 & $\begin{array}{c}427.0291 * * * \\
(111.5451)\end{array}$ & 0.000 \\
\hline MaxMatch & $\begin{array}{c}0.0247 \\
(0.0853)\end{array}$ & 0.773 & $\begin{array}{c}0.1100 \\
(0.2071)\end{array}$ & 0.597 \\
\hline IncentiveP & $\begin{array}{l}-1.4561 \\
(1.1491)\end{array}$ & 0.208 & $\begin{array}{c}26.3398^{* * * *} \\
(8.4455)\end{array}$ & 0.003 \\
\hline BasicP & $\begin{array}{l}-0.0878 \\
(0.1059)\end{array}$ & 0.409 & $\begin{array}{c}-0.8162 * * \\
(0.3563)\end{array}$ & -0.026 \\
\hline Income & $\begin{array}{c}0.0002 \\
(0.0005)\end{array}$ & 0.667 & $\begin{array}{c}0.0011 \\
(0.0025)\end{array}$ & 0.650 \\
\hline Urbanization & $\begin{array}{l}0.0008^{* * *} \\
(0.0832)\end{array}$ & 0.039 & $\begin{array}{l}0.9680^{* * *} \\
(0.2100)\end{array}$ & 0.000 \\
\hline MaleRatio & $\begin{array}{l}-7.4300^{* *} \\
(2.9797)\end{array}$ & 0.014 & $\begin{array}{c}-6.8526^{* * *} \\
(1.8849)\end{array}$ & 0.001 \\
\hline EldRate & $\begin{array}{c}0.2599 \\
(0.2562)\end{array}$ & 0.312 & $\begin{array}{c}0.6103 \\
(0.5023)\end{array}$ & 0.229 \\
\hline within & \multicolumn{2}{|c|}{0.1009} & \multicolumn{2}{|c|}{0.0011} \\
\hline $\mathrm{R}^{2}$ : between & \multicolumn{2}{|c|}{0.3655} & \multicolumn{2}{|c|}{0.6140} \\
\hline overall & \multicolumn{2}{|c|}{0.3623} & \multicolumn{2}{|c|}{0.5207} \\
\hline
\end{tabular}

Notes: Standard errors are presented in parentheses; ${ }^{*}$ significant at $10 \%$; ${ }^{* *}$ significant at $5 \%$; ${ }^{* * *}$ significant at $1 \%$. 
The between-effects regression results imply that average individual contributions in the counties with an incentive pension are significantly higher than that of the counties without an incentive pension. However, this effect is not significant in the fixed-effects regression when controlling for county-specific effects, meaning that the provision of incentive pension cannot increase the individual contributions significantly. Increasing the amounts of maximum matching subsidy cannot increase the contributions significantly either. A higher degree of urbanization can increase individual contributions but the magnitude is small. The overall contribution is lower when the proportion of male residents increases. Average individual contributions in the counties with higher basic pension are lower than that in the counties with lower basic pension. This is probably because when the basic pension is higher, participants may rely on it more, and care less about the matching and contribution portion of the pension payment. An important difference between "fixed-effects" and "between-effects" estimators is that the fixed ("within") effects solves a number of endogeneity problems, which arise from time-invariant third factors, such as traditions, culture, and geography. In the context of counties in a Chinese province, endogeneity problems may arise because of transport infrastructure, existence of large factories/enterprises in the area, local administration, etc. [17]. These factors may affect both individual contributions and the key explanatory variables. Therefore, it seems that the fixed-effect estimates are more consistent than between-effect estimates, although the later offers some information about different effects of fiscal subsidies between counties. We also want to note that the software we used is STATA (StataCorp), and the fixed-effects results in STATA reports have simply been reformulated so that the reported intercept is the average value of the fixed effects.

\section{Discussion and Concluding Remarks}

In this paper, we study the effectiveness of fiscal subsides in improving the sustainability of rural pension system in China in terms of participation rates and individual contribution amounts. Our data show that participation rates of rural residents younger than 30 are significantly lower than that of older people. The results suggest that rural residents' participation rates in the pension system can be significantly improved either by providing a higher amount for the basic pension, or by providing an incentive pension that increases the pension payment as the number of years enrolled in the program increases. The significant effects of incentive pension do not differ among different age groups, although it is designed aiming to increase the participation rates of people younger than 45 . Neither of these two fiscal policies have any significant effects on improving the amount of contributions made. Moreover, increasing the maximum amount of the matching subsidy has no effect on participation rates and individual contributions. We do admit that a number of endogeneity problems exist in our analysis due to the lack of data when conducting this brief report. In our future study, we hope to acquire more county-level data to obtain adequate instrumental variables to address the endogeneity problem.

Overall, our results imply that incentive pension is an effective mechanism in encouraging rural residents to participate in the pension programs, but current level of matching subsidies is not sufficient enough to improve participation or increase contributions. China's rural pension payments in general are less than $10 \%$ of per capital rural income, which is significantly lower than the social pension in other countries [6]. Our study shows the need to increase the fiscal subsides in China's rural pension system, and can provide useful implications in designing an effective pension system for rural residents.

Author Contributions: Conceptualization, B.L. and Y.Y.Z.; Methodology, B.L. and Y.Y.Z.; Formal Analysis: B.L. and Y.Y.Z.; Writing, B.L. and Y.Y.Z. All authors have read and agreed to the published version of the manuscript.

Funding: Benxi Lin was supported by National Natural Science Foundation of China (Project No. 71303049) and Fujian Agriculture and Forestry University Science and Technology Innovation Special Fund (Project No. KFA17508A).

Acknowledgments: The authors would like to thank two anonymous reviewers for their great comments and suggestions, especially their insights regarding the endogeneity problems in our analysis. We would also like to thank the editor for her immense help in preparing this manuscript.

Conflicts of Interest: The authors declare no conflict of interest. 


\section{References}

1. China's Percentage of Elderly Highest in 2030. People's Daily, 12 September 2010. Available online: http://en.people.cn/90001/90776/90882/7137446.html (accessed on 13 November 2019).

2. United Nations. World Population Ageing 2017; United Nations: New York, NY, USA, 2017.

3. World Health Organization. China Country Assessment Report on Ageing and Health 2015; Department of Aging and Life Course, World Health Organization: Geneva, Switzerland, 2015.

4. Dorfman, M.C.; Wang, D.; O'Keefe, P.; Cheng, J. China's Pension Schemes for Rural and Urban Residents; Matching Contributions for Pensions, 217; World Bank Publications: Washington, DC, USA, 2013.

5. Scheffel, J.; Zhang, Y. How does internal migration affect the emotional health of elderly parents left-behind? J. Popul. Econ. 2019, 32, 953-980. [CrossRef]

6. Lin, B.; Lin, Z.; Zhang, Y.; Liu, W. The impact of the new rural pension scheme on retirement sustainability in China: Evidence of regional differences in formal and informal labor supply. Sustainability 2018, 10, 4366. [CrossRef]

7. Cai, F.; Giles, J.; O'Keefe, P.; Wang, D. The Elderly and Old Age Support in Rural China; World Bank Publications: Washington, DC, USA, 2012.

8. Dorfman, M.C.; Holzmann, R.; O’keefe, P.; Wang, D.; Sin, Y.; Hinz, R. China's Pension System: A Vision; World Bank Publications: Washington, DC, USA, 2013.

9. Ministry of Human Resources and Social Security of the People's Republic of China. Urban and Rural Residents' Pension Insurance Has Entered a New Era; Ministry of Human Resources and Social Security of the People's Republic of China: Beijing, China, 2018.

10. Lei, X.; Zhang, C.; Zhao, Y. Incentive problems in China's new rural pension program. In Labor Market Issues in China; Emerald Group Publishing Limited: Bingley, UK, 2013; pp. 181-201.

11. Chen, H.; Tang, L.; Qiu, Q.; Wu, T.; Wang, Z.; Xu, S.; Xiao, L. Coupling between rural development and ecosystem services, the case of Fujian Province, China. Sustainability 2018, 10, 524. [CrossRef]

12. Lyons, T.P. Intraprovincial disparities in China: Fujian province, 1978-1995. Econ. Geogr. 1998, 74, 405-432. [CrossRef]

13. Palacios, R.; Robalino, D.A. Matching Defined Contributions: A way to increase pension coverage. In Closing the Coverage Gap: The Role of Social Pensions and Other Retirement Income Transfers; World Bank Publications: Washington, DC, USA, 2009; pp. 187-202.

14. Hinz, R.; Holzmann, R.; Tuesta, D.; Takayama, N. (Eds.) Matching Contributions for Pensions: A Review of International Experience; World Bank Publications: Washington, DC, USA, 2012.

15. Ferrari, S.; Cribari-Neto, F. Beta regression for modelling rates and proportions. J. Appl. Stat. 2004, 31, 799-815. [CrossRef]

16. Fedotenkov, I.; Schneider, F. Military Expenditures and Shadow Economy in the Central and Eastern Europe: Is There a Link? Cent. Eur. Econ. J. 2019, 5, 142-153. [CrossRef]

17. Mundlak, Y. On the pooling of time series and cross section data. Econom. J. Econom. Soc. 1978, 46, 69-85. [CrossRef]

(C) 2019 by the authors. Licensee MDPI, Basel, Switzerland. This article is an open access article distributed under the terms and conditions of the Creative Commons Attribution (CC BY) license (http://creativecommons.org/licenses/by/4.0/). 